\title{
Energy of adsorption of an adsorbent in solving environmental problems
}

\author{
Dilnoza Jumaeva ${ }^{1, *}$, Akmal Abdurakhimov ${ }^{2}$, Khodjiakbar Abdurakhimov ${ }^{3}$, Nigora Rakhmatullaeva ${ }^{4}$, and Olimjon Toirov ${ }^{5}$ \\ ${ }^{1}$ Institute of General and Inorganic Chemistry of the Academy of Sciences of the Republic of Uzbekistan, DSc., Prof., Tashkent, 100170, \\ Uzbekistan \\ ${ }^{2}$ Institute of General and Inorganic Chemistry of the Academy of Sciences of the Republic of Uzbekistan, Tashkent, 100170, Uzbekistan \\ ${ }^{3}$ Gulistan State University, DSc., Prof., Sirdarya, Uzbekistan \\ ${ }^{4}$ Tashkent Institute of Chemical Technology, Tashkent, Uzbekista \\ ${ }^{5}$ Tashkent State Technical University, DSc., Prof. Head of the Department of Electrical machine, Tashkent, 100095, Uzbekistan
}

\begin{abstract}
The article presents the results of the study of the adsorption energy, thermodynamic parameters of adsorbents, which serve to solve the problems of ecology and environmental protection.Based on the results obtained, the adsorption mechanism of the pargaz activated carbon adsorbent on the basis of tree wood and waste stem was studied.The energy of the adsorption process of the adsorbent is obtained on the basis of data on the full thermodynamic parameters of the field of application of adsorbents. The paper examines the differential heat content, adsorption isotherm, entropy, and kinetics of PPAU-A experimentally. This article uses adsorption microcalorimetric methods of analysis. Paulownia tomentosa tree coal adsorbents according to the adsorption amounts of water molecules in thermally and steam-gas activated carbon adsorbents based on tree stems is as follows: PPAU-A> BAU-A.The value of the adsorption value of water vapor in PPAU-Ada Beryoze activated carbon was found to be 1.4 times higher than BAU-A.
\end{abstract}

\section{Introduction}

There are a number of factors leading to the conflicting state of ecology and environmental protection by industrial and manufacturing enterprises, the development of adsorbents with active surface, active adsorption properties to solve these problems, the study of their adsorption energy is one of the urgent problems. One of the main problems of ecology is the problem of environmentally hazardous wastes and atmospheric air pollution. Extraction of secondary raw materials from waste and its use in the elimination of environmental problems serve as a solution to the above problems.Therefore, in this research work, the aim was to obtain an activated adsorbent based on tree waste and to study their adsorption energy. As a result of studying the thermodynamics of the adsorption process in adsorbents, we obtain accurate information about their active surface area, adsorption mechanisms and complete thermodynamic parameters. In the study of thermodynamic processes, we gain insights into the mechanism of adsorption mainly by studying the adsorption heat, isotherm, kinetics, and entropy.

In adsorbents, the adsorption process is observed in the state of physical and chemical adsorption.

In both the physical adsorption process and the chemical adsorption process, a thermal effect is observed, in which the amount of heat is released as the adsorption event occurs by an exothermic process, i.e. heat dissipation. The amount of heat released during the course of chemical adsorption is very close to the thermal effect of chemical reactions. In the case of physical adsorption, the amount of heat released is mainly measured using a microcalorimeter device.

In this case, the results obtained as a result of the experiment have an approximate value, because the adsorption process and the time of heat dissipation last for a certain period of time. The thermal effect occurring in the adsorption phenomenon is analyzed by concepts such as integral heat and differential heat of adsorption, as well as formulas for their determination by mathematical operations.

\section{Literature Review}

Adsorption heat can be determined using microcalorimetric devices based on a very sensitive adiabatic process [ 1 ]. The exact values of the adsorption isotherms and the differential heat of adsorption can be used to determine the differential molar entropy $(\Delta \mathrm{Sd})$ of adsorption using the Gibbs-Helmholtz equation [2-4].

Adsorption of benzene and toluene vapor as adsorbents from organic substances to natural mineral compounds, ie bentonites, mainly from adsorbents, as well as thermodynamic parameters were studied [5-10] defined. In the adsorption of synthetic zeolites, the full thermodynamic parameters of the adsorption of benzene,

\footnotetext{
* Corresponding author: d.jumayeva@list.ru
} 
water and SO2 gas vapors from adsorbates were studied and the adsorption mechanism was determined on their basis [11-13]. However, to date, the literature does not provide accurate information on the adsorption and thermodynamic parameters of adsorbents based on the tree, the mechanism of adsorption.

Studies on adsorbents obtained as a result of activation of various tree species make up a very small amount [14-21]. As a result of determining the adsorption mechanism using thermodynamic parameters of adsorbents, experimental studies were carried out on a high-vacuum adsorption microcalorimetric device in order to obtain information about their active surface surfaces and selective adsorption capacity. The adsorbent mechanism of water quadrupol molecule vapors belonging to the class of aromatic hydrocarbons to the carbon adsorbent obtained by steam-gas activation method on the basis of Paulownia tomentosa tree stem was obtained, energy characteristics of molecular interactions between adsorbent-adsorbate and adsorbateadsorbate. The following authors [22-26] have dealt with the issues of energy, electrical mechanisms and the energy of adsorption of the adsorbent.

\section{Research methods}

This article uses adsorption microcalorimetric methods of analysis. In determining the thermodynamic parameters of adsorbents with high adsorption activity, the process of studying the adsorption mechanism used a universal high-vacuum adsorption device at a temperature of $303 \mathrm{~K}$ and a system of differential microcalorimeter type Tiana-Kalve DAK-1-1A connected to it.

Using the device, the values of the isotherm, differential heat content, entropy and kinetics of water vapor adsorption on the adsorbent PPAU-A (Paulownia pargaz activated carbon adsorbent) were obtained.

\section{Results and discussion}

In the adsorption-calorimetric method, an adsorbent sample with a dispersion of $2-5 \mathrm{~mm}$, which is activated in the study of thermodynamic characteristics of adsorbents water vapor adsorption, is placed in a glass ampoule, and in turn the finished ampoule is connected to the calorimeter.

Initially, the vacuum is connected to the vacuum pump at a temperature of $423 \mathrm{~K}$ for 4 hours until a residual pressure of $10^{-5} \mathrm{~Pa}$ is reached. The quadrupol water molecule selected as the adsorbate was first frozen and then the dissolved gases were removed using a vacuum pump at room temperature. The adsorption process is carried out at a temperature of $303 \mathrm{~K}$.

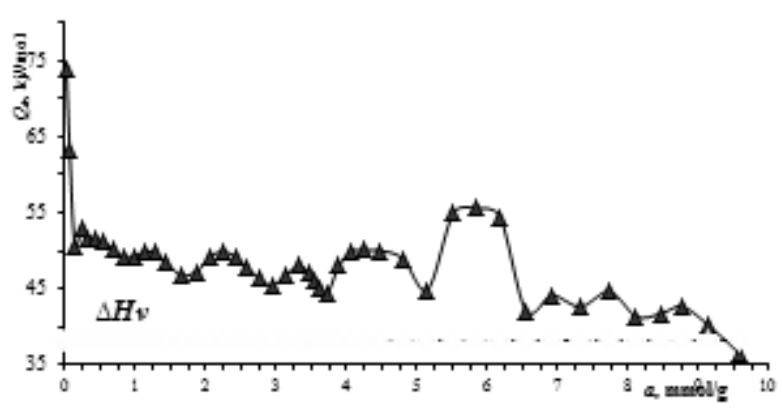

Fig. 1. Differential heat of adsorption of water vapor on PPAUA adsorbent $\mathrm{Hv}$ is the heat of condensation of water vapor at $303 \mathrm{~K}$ on the horizontal line.

The results of the differential thermal adsorption of pargaz activated carbon adsorbent are shown in Figure 1. In the PPAU-Ada water adsorption heat in the initial saturation areas, when the adsorption amount $\mathrm{a}=0.14$ $\mathrm{mmol} / \mathrm{g}$, the $\mathrm{Q}_{d}$ differential heat value started from 74.0 $\mathrm{kJ} / \mathrm{mol}$, a sharp decrease was observed, and the $\mathrm{Q}_{d}$ value was equal to $50.51 \mathrm{~kJ} / \mathrm{mol}$. In the subsequent adsorption stages, the process changes in a stepwise manner through the maximum.

The results of the experimental study showed that with increasing value of the amount of adsorbent in the adsorbent, the differential heat at $\mathrm{a}=0.83 \mathrm{mmol} / \mathrm{g}$ reaches the value of $\mathrm{Q}_{d}=49.1 \mathrm{~kJ} / \mathrm{mol}$, and a small saturation of the first step passes through the maximum. The reason for the high heat at such small saturations is due to the formation of $\mathrm{p}$-complexes with water molecules with small amounts of rare metal cations in the carbon adsorbent sample. As the amount of adsorption in the adsorbent increased to $\mathrm{a}=1.65$ $\mathrm{mmol} / \mathrm{g}$, a stepwise decrease in the amount of differential heat was observed to $\mathrm{Q}_{d}=46.78 \mathrm{~kJ} / \mathrm{mol}$. In such a saturation state, the electron acceptor formed during the vapor-gas activation of the carbon adsorbent falls into the field of formation due to the interaction of carbon atoms with water molecules. Then, in the next stage, the amount of differential heat decreases to $Q d=$ $45.4 \mathrm{~kJ} / \mathrm{mol}$ when the amount of adsorption increases in the range $\mathrm{a}=1.65 \div 2.94 \mathrm{mmol} / \mathrm{g}$, and then the differential heat of adsorption increases when the amount of adsorption increases to a $=3.60 \mathrm{~mol} / \mathrm{kg}$. An insignificant decrease was observed through the maximum to $\mathrm{Q}_{d}=$ $45.0 \mathrm{~kJ} / \mathrm{mol}$. Then, as a result of the change in the amount of adsorption in the range $\mathrm{a}=5.2 \div 6.55 \mathrm{mmol} / \mathrm{g}$, the change in the differential heat of adsorption to $\mathrm{Q}_{d}=$ $44.87 \div 42.13 \mathrm{~kJ} / \mathrm{mol}$ was observed with a high maximum, while the amount of differential heat $\mathrm{Q}_{d}=$ $55.6 \mathrm{~kJ} / \mathrm{mol}$ as a result of rising to the top was observed a sharp high maximum. During the next stages of the adsorption process, a decrease in the amount of heat of adsorption was observed between small maxima in the range $\mathrm{Q}_{d}=42.13 \div 40.13 \mathrm{~kJ} / \mathrm{mol}$ in the range of adsorption amount $\mathrm{a}=6.55 \mathrm{mmol} / \mathrm{g}$ to $9.1 \mathrm{mmol} / \mathrm{g}$. At the end of the adsorption, when the amount reached $\mathrm{a}=9.56$ $\mathrm{mmol} / \mathrm{g}$, a decrease in the heat value of condensation was observed. Such a decrease in the heat of adsorption corresponds to a decrease in the potential energy in the 
adsorbent due to the occurrence of adsorption on the micro-, and meza-pores in the empty state of the adsorbent, as well as the filling of the pores with adsorbent molecules. Since the porosity of carbon-based adsorbents is very small, sunken mensk is formed in such pores. In these mensks, the adsorbent vapors condense at pressures below the saturation pressure $\left(\mathrm{P}_{\mathrm{s}}\right)$ on the flat surface.

At this time, the adsorbent initially forms polymolecular layers on the capillary walls, which accumulate and become a liquid that moistens the capillary and fills it. In this case, capillary condensation occurs not under the influence of adsorption forces, but under the influence of the force of attraction of vapor molecules to the spherical surface of the liquid. In the last saturation areas of adsorption, the adsorption heat was observed to decrease in the range $\mathrm{a}=9.56 \mathrm{mmol} / \mathrm{g}$ to $\mathrm{Q}_{d}=36.65 \mathrm{~kJ} / \mathrm{mol}$. This indicates that the final stages of adsorption occur due to the adsorbate-adsorbate interaction, where the thermal value of the adsorption is small.

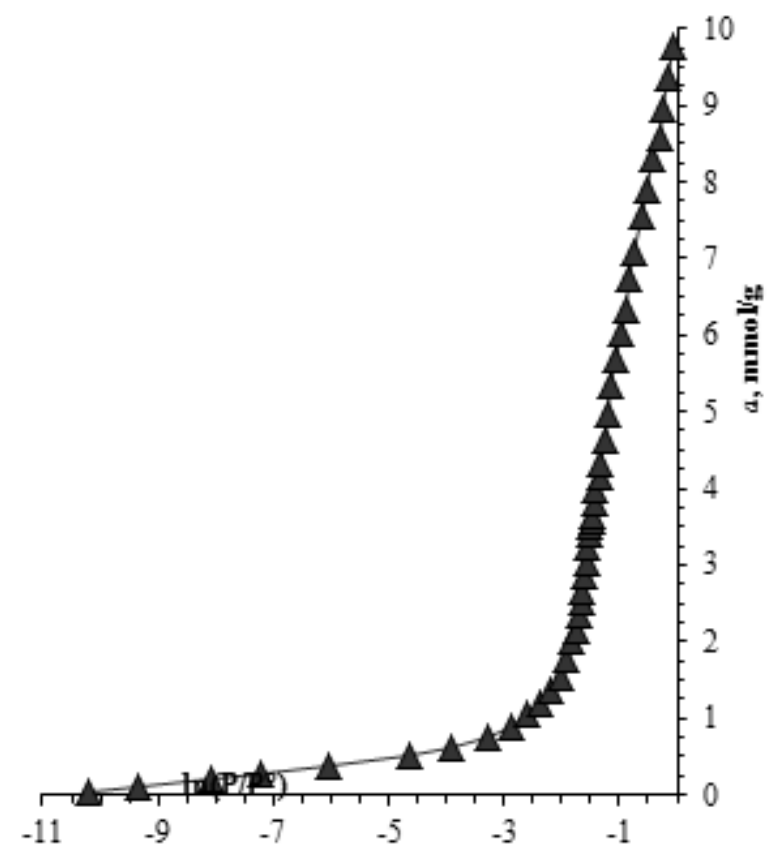

Fig. 2. Isotherm of water vapor adsorption in PPAU-A adsorbent.

The results of the adsorption isotherm of PPAU-A based on experiments at $303 \mathrm{~K}$ are shown in Figure 2.

The differential entropy value of adsorption describes the motion of a certain number of adsorbed molecules in the adsorbent, the state function. The entropy curve of the PPAU-A and $\mathrm{H}_{2} \mathrm{O}$ system has a wavy appearance according to the adsorbent saturation values, and the quadrupol molecule selected as the adsorbate in the adsorbent provides information on the location of the water (Fig. 3).

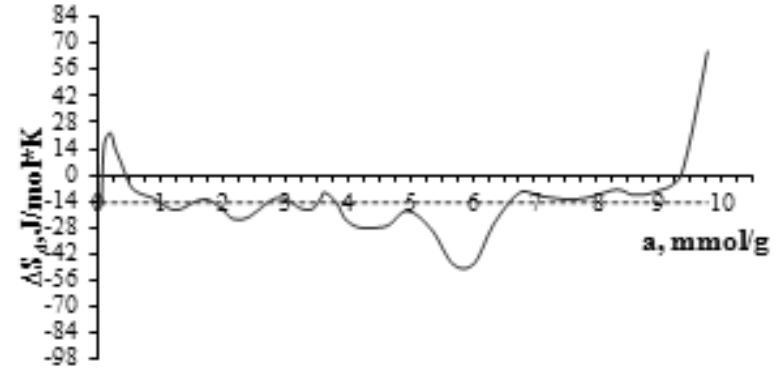

Fig. 3. Differential entropy of adsorption of water vapor molecule on PPAU-A adsorbent.

The maximum level of differential entropy value expressed in molar value of adsorption in the adsorbent was in the range of positive entropy value $\Delta S=22.6$ $\mathrm{J} /(\mathrm{mol} * \mathrm{~K})$ in the areas of formation of $\mathrm{p}$-complexes. It was then observed that in the PPAU-A- $\mathrm{H}_{2} \mathrm{O}$ system at negative values of adsorption entropy, the amount of adsorption between 0.5 and $4.96 \mathrm{mmol} / \mathrm{g}$ passes through small minimum rings with entropy value $\Delta \mathrm{S}=$ $19.02 \mathrm{~J} /\left(\mathrm{mol}^{*} \mathrm{~K}\right)$.

This state of entropy leads to the conclusion that the water molecules absorbed by the adsorbent are motionless, i.e., in a solid state. At values of entropy adsorption value $6.02 \mathrm{mmol} / \mathrm{g}$, the value of entropy $\Delta \mathrm{S}=$ $-47.52 \mathrm{~J} /(\mathrm{mol} * \mathrm{~K}$ was reduced to a high minimum.

In the next view of entropy, it was observed that the value of entropy ranged from $6.75 \mathrm{mmol} / \mathrm{g}$ to 9.35 $\mathrm{mmol} / \mathrm{g}$ at a negative value between $\Delta \mathrm{S}=-7.0 \mathrm{~J} /\left(\mathrm{mol}^{*} \mathrm{~K}\right)$.

At the end of the adsorption entropy, a sharp maximum was observed, and when the adsorption amount reached $9.77 \mathrm{mmol} / \mathrm{g}$, the positive value of entropy increased to $\mathrm{S}=66.0 \mathrm{~J} /\left(\mathrm{mol}^{*} \mathrm{~K}\right)$. The motion of the water molecules then equals the motion of the molecules in the liquid state due to capillary condensation in the adsorbent mesocytes. The results of the dependence of the time of formation of the adsorption equilibrium in the PPAU-A adsorbent on the adsorption are shown in Figure 4.

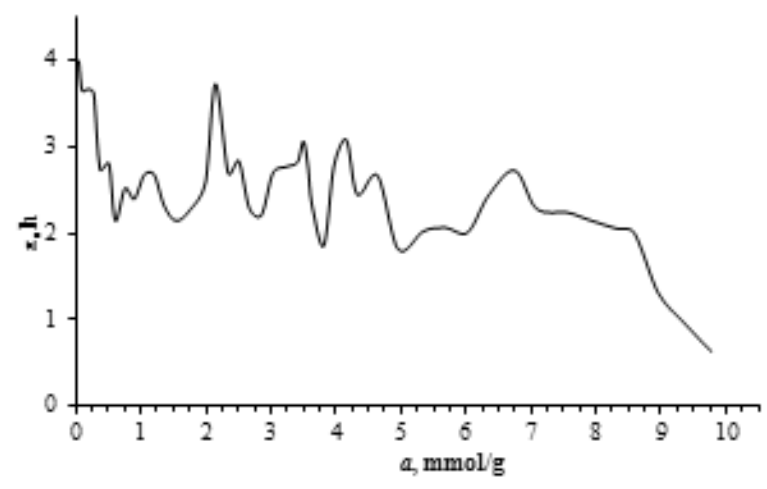

Fig. 4. Changes in the kinetics of water vapor adsorption on PPAU-A adsorbent.

The setting time of the adsorption equilibrium in the areas of formation of the first p-complexes lasted up to 4 $\mathrm{h}$. With an increase in adsorption, a decrease in adsorption time to 2 hours was observed in the wavy 
form. The total adsorption rate $\mathrm{a}=9.77 \mathrm{mmol} / \mathrm{g}$ was observed with maximum and minimum duration, and in the final saturation state of the adsorption, ie at $t \approx 0.5 \mathrm{~h}$, the adsorption was completed.

\section{Conclusion}

Based on the generalization and analysis of the obtained results, the range of imported analog and Paulownia tree coal adsorbents according to the adsorption amounts of water molecules in thermally and steam-gas activated carbon adsorbents based on tree stems is as follows: PPAU-A > BAU-A.The value of the adsorption value of water vapor in PPAU-Ada (Beryoze activated carbon) was found to be 1.4 times higher than BAU-A.

\section{References}

1. P.L. Llewellyn, G. Maurin, Gas adsorption microcalorimetry and modelling to characterise zeolites and related materials, Comptes Rendus Chimie, 8 (3-4), 283-302 (2005) DOI: 10.1016/j.crci.2004.11.004

2. M.H. Chiu, El.J. Prenner, Differential scanning calorimetry: An invaluable tool for a detailed thermodynamic characterization of macromolecules and their interactions, 3 (1), 3959 (2011)

3. Mujib, L. Palashab, Tahmid Hasan Rupamab, Animesh Palc, Anutosh Chakrabortyd, Bidyut Baran Saha, Ruzhu Wange, Design principles for synthesizing high grade activated carbons for adsorption heat pumps, 6, (2021) DOI: 10.1016/j.ceja.2021.100086

4. H. Xu, L. Prasetyo, D.D. Do, D. Nicholson, The Henry constant and isosteric heat at zero loading for adsorption on energetically heterogeneous solids absolute versus excess, Chem. Eng. J., 395 (2020)

5. L. Prasetyo, D.D. Do, D. Nicholson, A coherent definition of Henry constant and isosteric heat at zero loading for adsorption in solids - an absolute accessible volume, Chem. Eng. J., 334, 143-152 (2018)

6. A. Chakraborty, B.B. Saha, S. Koyama, K.C. Ng, On the thermodynamic modeling of the isosteric heat of adsorption and comparison with experiments, Appl. Phys. Lett., 89 (2006)

7. C.O. Areán, D. Nachtigallová, P. Nachtigall, E. Garrone, M.R. Delgado, Thermodynamics of reversible gas adsorption on alkali-metal exchanged zeolites-the interplay of infrared spectroscopy and theoretical calculations, Phys. Chem. Chem. Phys., 9, 1421-1437 (2007)

8. S. Cloete, A. Giuffrida, M.C. Romano, A. Zaabout, The effect of sorbent regeneration enthalpy on the performance of the novel swing adsorption reactor cluster (SARC) for postcombustion $\mathrm{CO}_{2}$ capture, Chem. Eng. J., 377 (2019)
9. S.J. Tan, D. Nicholson, An efficient kinetic Monte Carlo scheme for computing Helmholtz free energy and entropy in bulk fluids and adsorption systems, Chem. Eng. J., 334, 14101421 (2018)

10. T.H. Rupam, M.A. Islam, A. Pal, A. Chakraborty, B.B. Saha, Thermodynamic property surfaces for various adsorbent/adsorbate pairs for cooling applications, Int. J. Heat Mass Transf., 144 (2019)

11. T.H. Rupam, M.A. Islam, A. Pal, B.B. Saha, Adsorption thermodynamics and performance indicators of selective adsorbent/refrigerant pairs, Appl. Therm. Eng., 175 (2020)

12. R.K. Agarwal, K.A.G. Amankwah, J.A. Schwarz, Analysis of adsorption entropies of high pressure gas adsorption data on activated carbon, Carbon N. Y., 28, 169-174 (1990)

13. L. Yu, L. Hu, B. Anasori, Y.-T. Liu, Q. Zhu, P. Zhang, Y. Gogotsi, B. Xu, MXene-bonded activated carbon as a flexible electrode for highperformance supercapacitors, ACS Energy Lett, 3, 1597-1603 (2018)

14. Sabino De Gisia Giusy Lofranoab Mariangela Grassib Michele Notarnicolaa, Characteristics and adsorption capacities of low-cost sorbents for wastewater treatment: A review, Sustainable Materials and Technologies, 10-40 (2016)

15. C. Kim, Y.-K. Choe, D.H. Won, U. Lee, H.-S. Oh, D.K. Lee, C.H. Choi, S. Yoon, W. Kim, Y.J. Hwang, B.K. Min, Turning harmful deposition of metal impurities into activation of nitrogen-doped carbon catalyst toward durable electrochemical $\mathrm{CO}_{2}$ reduction, ACS Energy Lett, 4, 2343-2350 (2019)

16. Z. Yin, C. Cui, H. Chen, X.Yu Duoni, W. Qian, The application of carbon nanotube/graphenebased nanomaterials in wastewater treatment Small, 16 (2020)

17. A. Pal, M.S.R. Shahrom, M. Moniruzzaman, C.D. Wilfred, S. Mitra, K. Thu, B.B. Saha, Ionic liquid as a new binder for activated carbon based consolidated composite adsorbents, Chem. Eng. J., 326, 980-986 (2017)

18. El-Sharkawy, K. Uddin, T. Miyazaki, B.B. Saha, S. Koyama, J. Miyawaki, S.-H. Yoon. Adsorption of ethanol onto parent and surface treated activated carbon powders. Int. J. Heat Mass Transf., 73, 445-455 (2014)

19. El-Sharkawy, K. Uddin, T. Miyazaki, B.B. Saha, S. Koyama, H.-S. Kil, S.-H. Yoon, J. Miyawaki, Adsorption of ethanol onto phenol resin based adsorbents for developing next generation cooling systems, Int. J. Heat Mass Transf., 81, 171-178 (2015)

20. D. Jumayeva, I. Eshmetov, B. Jumabaev, A. Agzamkhodjayev, Carbon adsorbents on the basis of Brown coal of Angren for cleaning industrial wastewater, Journal of Chemical Technology and Metallurgy, 51 (2), 210-214 (2016)

21. D. Jumaeva, I. Eshmetov, B. Jumabaev, A. Agzamkhodjaev, Coal adsorbents for sewage treatment, European Conference on Innovations 
in Technical and Natural Sciences, Austria, Vena, 104-109 (2015)

22. D. Bystrov, T. Olimjon, Mustafakulova Gulzoda, Yakubova Dilfuza NISS2020: Proceedings of the 3rd International Conference on Networking, Information Systems \& Security, 54, 1-3 (2020) DOI: $10.1145 / 3386723.3387873$

23. D. Bystrov, T. Olimjon, G. Sanjar, T. Mirzokhid, U. Sardor, NISS2020: Proceedings of the 3rd International Conference on Networking, Information Systems \& Security, 49, 1-4 (2020) DOI: $10.1145 / 3386723.3387868$

24. O. Toirov, A. Bekishev, S. Urakov, U. Mirkhonov, E3S Web of Conferences, 216, 01116 (2020) DOI: 10.1051/e3sconf/202021601116

25. O. Toirov, K. Alimkhodjaev, N. Pirmatov, A. Kholbutaeva, E3S Web of Conferences, 216, 01119 (2020) DOI: $10.1051 /$ e3sconf/202021601119

26. H. Afrisal, B. Setiyono, M. Fahmi, Y. Rose, M. Suin, O. Toirov, 7th International Conference on Information Technology, Computer, and Electrical Engineering (ICITACEE), 41-46 (2020)

DOI:

10.1109/ICITACEE50144.2020.9239228. 